\title{
PROBLEM ONTOLOGY PEDAGOGIK INDONESIA
}

\author{
${ }^{1)}$ Mamat Supriatna \\ ${ }^{1)}$ Program Studi Bimbingan dan Konseling Fakultas Ilmu Pendidikan \\ Universitas Pendidikan Indonesia \\ ma2t.supri@upi.edu
}

\begin{abstract}
Pedagogical discourse in Indonesia is inseparable from the development of the nation's history. Throughout the nation's history, pedagogical discourse in Indonesia remains stagnant as the object of its study is continued to reside on the practical level of education. Academicians, policy makers, observers, and practitioners of education still do not care about foundational and structural objects of the study that contribute to the sturdiness of the scientific foundation and the education system. This paper aims to analytically describe the problem of the ontology of the science education, which focuses on aspects of the scope and boundaries of the research paper. Therefore, this paper is expected to stimulate research and development of science and praxis of education.
\end{abstract}

Key words: transformative pedagogic, foundational, structural, operational.

\section{A. PENDAhULUAN}

Praksis pendidikan di Indonesia berhadapan dengan tantangan internal dalam wujud penyiapan Generasi Emas, yang sejalan dengan 100 tahun usia kemerdekaan negara ini pada 2045. Generasi Emas adalah generasi pengisi pertengahan dan akhir Abad XXI di Indonesia, yang diantisipasi harus memiliki karakteristik produktif, kreatif, inovatif, dan afektif. Karakteristik generasi tersebut dikembangkan melalui pendidikan yang berbasis kokoh pada kreativitas yang melahirkan inovasi, dan moralitas yang mengawal mereka agar dapat menghadapi tantangan masa depan kehidupannya.

Kendati masa depan itu belum dan mungkin dialami, akan tetapi karakteristik pribadi pengisinya harus sudah terumuskan dalam tujuan pendidikan, dan secara deskriptif dapat dianalisis melalui kajian empirik yang komprehensif. Dengan begitu, praksis pendidikan bukan hanya dilandasi oleh kebijakan yang dihasilkan di belakang meja, melainkan ditunjang oleh hasil kajian ilmu pendidikan (pedagogik) yang mencakup (Rochman Natawidjaja, 2007): (1) perkembangan dan perwujudan fitrah dan seluruh potensi manusia sepanjang hayat yang terjadi dalam setiap unit kehidupan yang difasilitasi dalam berbagai jalur, jenis, jenjang, dan satuan pendidikan; (2) pertumbuhan kepribadian yang utuh dan seimbang; (3) pendewasaan manusia dalam mencapai kebaikan dan kemaslahatan hidup dunia dan akhirat; (4) pemanusiaan manusia; (5) penghalusan budi dan pembinaan akhlak mulia agar memancarkan sinar ilahiah; dan (6) pembangunan kualitas pribadi dan kecerdasan manusia, serta karakter bangsa.

Praksis pendidikan yang dimaksud perlu didukung dan dilandasi kajian keilmuan yang handal. Dengan kata lain, penelitian ilmiah dapat berkontribusi signifikan terhadap upaya pemenuhan kebutuhan tersebut. Sayangnya, dengan telaahan pendekatan filsafat keilmuan, penelitian di bidang pendidikan selama ini mengindikasikan masih mengandung berbagai keterbatasan dan kelemahan, baik secara ontologis, epistemologis, maupun aksiologis (Abin Syamsuddin Makmun, 2004). Dari segi ontologis, penelitian pendidikan lebih berfokus pada kajian ranah operasional persekolahan; segi epistemologis cenderung masih berorientasi pada pendekatan disipliner konvensional; dan segi aksiologis cenderung masih kurang mengindahkan etika normatif dalam proses operasionalnya, serta jangkauan akses pendayagunaan hasil dalam menunjang 
pengembangan ilmu dan penyempurnaan praksis pendidikan belum merasuk ke arah sasaran.

\section{B. STUDI LITERATUR}

Dari pertengahan hingga akhir Abad XX, pedagogik di Indonesia tidak jelas eksistensinya. Dalam tataran dunia ilmu, istilah pedagogik (sebagai sebutan ilmu pendidikan) itu sendiri tidak tercatat di dalam "Encyclopedia of the Scientific Revolution," yang berjumlah halaman 1244 dan diedit Wilbur Applebaum (2000). Padahal awal Abad XX, Brezinka (1992), mengungkapkan hasil kajian tentang pedagogik secara komprehensif, dalam Philosophy of Educational Knowledge, London: Kluwer Academic Publishers. Hal ini dapat diartikan bahwa pedagogik mengalami evolusi ketidakjelasan, baik di Indonesia maupun dalam percaturan dunia ilmu pada umumnya. Pantaslah kalau dua dekade yang lalu Mochtar Buchori (1994), secara provokatif melontarkan, "Lonceng Kematian bagi Ilmu Pendidikan di Indonesia."

Kondisi pedagogik yang demikian ditafsirkan oleh Tilaar (2012), disebabkan karena praksis pendidikan di Indonesia berjalan dalam keadaan "business as usual." Berarti sejak masa sebelum kolonial, pada masa kolonial, masa kebangkitan pertama dengan lahirnya gerakan kebangsaan, masa proklamasi hingga saat ini, pedagogik atau ilmu pendidikan di Indonesia tidak pernah dipersoalkan landasan teoretiknya. (Lihat Tabel 1).

\section{TABEL 1 ORIENTASI PEDAGOGIK INDONESIA}

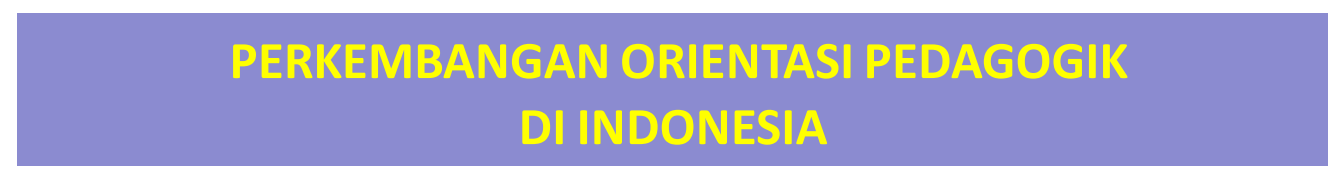

\begin{tabular}{|c|c|c|c|}
\hline Era & Periode & Orientasi & Keterangan \\
\hline Kolonial & $\begin{array}{l}1900-1942 \\
1942-1945 \\
\text { (Pendudukan Jepang) }\end{array}$ & $\begin{array}{l}\text { Rasionalisme } \\
\text { Aktivisme } \\
\text { Child-centered } \\
\text { Militarisme }\end{array}$ & $\begin{array}{l}\text { Herbartian } \\
\text { Decroly } \\
\text { Montessori } \\
\text { Kerschensteiner }\end{array}$ \\
\hline Poskolonial & $1945-1955$ & $\begin{array}{l}\text { Personalisme } \\
\text { Eksistensialisme } \\
\text { Teologisme }\end{array}$ & $\begin{array}{l}\text { Kohnstamm } \\
\text { Langeveld } \\
\text { Hoogveld }\end{array}$ \\
\hline Kemerdekaan & $\begin{array}{l}1955 \text { - } 1960 \\
1959 \text { - } 1965 \\
\text { Orde Lama } \\
1965 \text { - } 1997 \\
\text { Orde Baru } \\
\text { 1997 - } \\
\text { Orde Reformasi }\end{array}$ & $\begin{array}{l}\text { Pragmatisme } \\
\text { Instrumentalisme } \\
\text { Etatisme } \\
\text { Nasionalisme } \\
\text { Developmentalisme } \\
\text { Sentralisme } \\
\text { Liberalisme } \\
\text { Multikulturalisme }\end{array}$ & $\begin{array}{l}\text { Amerikanisme } \\
\text { Desentralisasi } \\
\text { Otonomi }\end{array}$ \\
\hline
\end{tabular}

*)Diolah dari Sumber Tilaar (2012) 
Bagi kalangan akademisi atau ilmuwan yang bergerak dalam bidang pendidikan, tentu saja kondisi seperti itu menjadi peluang dan tantangan. Apalagi bila diperhadapkan dengan kasus dan fenomena anomali praksis pendidikan saat ini. Ke depan memang diperlukan rumusan tentang pedagogik transformatif seirama dengan laju perkembangan negara dan bangsa Indonesia.

Dengan mencermati perkembangan orde reformasi di Indonesia, yang ditandai dengan desentralisasi dan otonomi, tampaknya orientasi pedagogik ke depan harus mencerminkan "Bhinneka Tunggal Ika" sebagai karunia rahmat dari Tuhan Yang Maha Esa. Orientasi pedagogik desentralisasi mengandung makna tanggung jawab kepemimpinan distributif dalam mengelola sistem pendidikan nasional; sedangkan otonomi bermakna strategi makro pendidikan yang diarahkan kepada pengembangan kekhasan dan kemandirian bangsa Indonesia. Artinya, blue print pendidikan nasional harus berlandasan filosofis dan kultural yang menjamin bahwa manusia Indonesia yang bermartabat dan berdaulat tidak tercerabut dari akar budaya sebagai bangsa Indonesia.

Demikian pula dengan arah pedagogik transformatif yang diharapkan terwujud tidak lepas dari landasan filosofis dan kultural Indonesia. Dalam praksis pendidikan, pedagogik transformatif merupakan upaya pengembangan manusia Indonesia dari kondisi apa adanya kepada yang seharusnya (Sunaryo Kartadinata, 2011; 2012).

Pedagogik transformatif harus dipandang sebagai salah satu manifestasi keunggulan bangsa Indonesia, khususnya ilmuwan pendidikan. Untuk itu diperlukan pengawalan dalam penumbuhkembangan pedagogik transformatif. Diilhami terbentuknya konsep, sekurang-kurangnya pengembangan pedagogik transformatif ditandai dengan adanya istilah, bentuk, dan kegiatan yang sering diungkapkan.

\section{METODE PENELITIAN}

Studi ini menggunakan metode analisis framing atau analisis isi mengenai fenomena permasalahan otology dari sebuah kajian pedagogia di dalma dunia pendidikan. OBjek kajian merupakan dokumentasi dan pendekatan interpretasi peneliti selama konteks ontology menjadi focus analisisnya.

\section{HASIL PENELITIAN DAN PEMBAHASAN}

Pedagogik sebagai ilmu pendidikan di Indonesia berhadapan dengan problem ontologik. Problem yang dimaksud berhubungan dengan objek kajian atau bidang telaahan yang tidak berkembang secara fundasional dan struktural. Mochtar Buchori (1994), telah menawarkan model matriks ontologik dengan menggunakan dua gugus variabel determinan untuk membatasi dan menentukan situs dan fokus telaahan bidang ilmu pendidikan. Kedua gugus variabel determinan itu meliputi: (I) bidang permasalahan esensial kependidikan, dan (II) arena (setting) lingkungan (milieu) sosiokultural di mana peristiwa (events) pendidikan itu mungkin muncul atau terjadi. Gugus variabel determinan pertama diorganisasikan ke dalam tiga kategori bidang permasalahan yang mencakup: (1) permasalahan fundasional (filosofis, teoretis, politis, ekonomis, dan sebagainya); (2) permasalahan struktur (jalur, jenjang, jenis struktural kelembagaan, organisasional dan manajerial, dan sebagainya); permasalahan operasional (kurikulum, sistem pembelajaran, pembimbingan, penilaian, dan sebagainya). Adapun gugus variabel determinan kedua juga dibagi ke dalam tiga kategori, yaitu: (1) lingkungan keluarga; (2) lingkungan sekolah; dan (3) lingkungan masyarakat. 


\section{TABEL 2 PERMASALAHAN ONTOLOGI PEDAGOGIK}

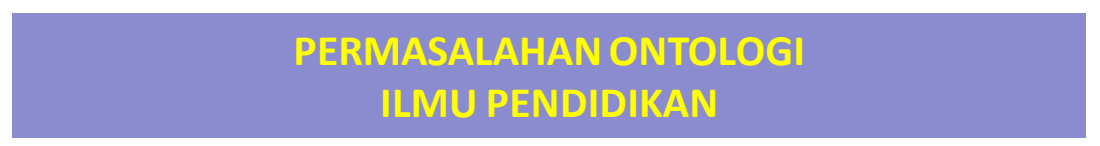

\begin{tabular}{|l|c|c|c|}
\hline $\begin{array}{l}\text { LINGKUNGAN } \\
\text { BIDANG } \\
\text { PERMASALAHAN }\end{array}$ & KELUARGA & SEKOLAH \\
\hline FUNDASIONAL & $\mathbf{1}$ & $\mathbf{2}$ & $\mathbf{3}$ \\
\hline STRUKTURAL & $\mathbf{4}$ & $\mathbf{5}$ & $\mathbf{6}$ \\
\hline & & & \\
\hline OPERASIONAL & $\mathbf{7}$ & 8 & $\mathbf{9}$ \\
\hline
\end{tabular}

\section{E. SIMPULAN DAN REKOMENDASI}

Selama ini upaya telaahan, kajian atau penelitian pendidikan di Indonesia sebagian besar baru tercurah pada bidang permasalahan operasional pendidikan di lingkungan persekolahan (mulai TK/SD hingga PT). Sementara kajian terhadap ranah lainnya masih terhitung langka dan terbatas. Padahal kajian fundasional dan struktural akan berkontribusi signifikan terhadap kekokohan landasan keilmuan dan sistem pendidikan nasional. Di samping itu, secara objektif anak-anak bangsa ini mengalami interaksi pedagogis, baik formal, non-formal maupun informal yang berlangsung sepanjang siang dan malam pada ketiga milieu keluarga, sekolah dan masyarakat. Bagaimanapun proyeksi manusia Indonesia masa depan bergantung pada kebijaksanaan keputusan masa kini.*(Bandung, 10102014)

\section{E. REFERENSI}

1. Abin S.M. 2004. Konsep Pendidikan dan Pembelajaran Kebutuhan Penelitian di Bidang Ilmu Pendidikan. Bandung: Universitas Pendidikan Indonesia.

2. Applebaum, W. (Ed). 2000. Encyclopedia of the Scientific Revolution. New York \& London: Garland Publishing, Inc.

3. Brezinka, W. 1992. Philosophy of Educational Knowledge. London: Kluwer Academic Publishers. 
4. Mochtar B. 1994. Ilmu Pendidikan dan Praktek Pendidikan. Jakarta: IKIP Muhammadiyah Press.

5. Rochman N., dkk. (Eds.). 2007. Rujukan Filsafat, Teori, dan Praksis Ilmu Pendidikan. Bandung: Universitas Pendidikan Indonesia Press.

6. Sunaryo K. 2011. Resureksi ilmu pendidikan dan penyehatan Kultur pendidikan. Bandung: Universitas Pendidikan Indonesia.

7. Sunaryo K. 2012. Penyehatan Kultur Pendidikan. Bandung: Universitas Pendidikan Indonesia.

8. Undang-Undang RI Nomor 20 Tahun 2003 Tentang Sistem Pendidikan Nasional.

9. H.A.R. Tilaar. 2012. Perubahan Sosial dan Pendidikan: Pengantar Pedagogik Transformatif untuk Indonesia. Jakarta: PT Rineka Cipta.

*) Mamat Supriatna: Tim dosen Landasan Pedagogik dan Etnopedagogik dari Departemen Psikologi Pendidikan dan Bimbingan, FIP-UPI. 